\title{
1 Variation in the allometry of exaggerated rhinoceros beetle horns
}

3 Running header: Allometry of rhinoceros beetle horns

\section{Abstract}

7 Exaggerated horns are a characteristic feature of many male rhinoceros beetles. We

8 surveyed and compared the scaling relationships of these sexually-selected

9 weapons for 31 Dynastinae species with different degrees of horn exaggeration. We

10 found that nearly all rhinoceros beetle species were male dimorphic, that the

11 allometric slope of major males was consistently shallower than the slope of minor

12 males, and that the decrease in slope was greatest among species with the most

13 exaggerated horns. These patterns are consistent with the curved allometries of stag

14 beetle mandibles and giraffe weevil rostra, and suggest that the depletion of

15 developmental resources is a general phenomenon limiting the continued

16 exaggeration of insect weapons. The dimorphisms in horn morphology are expected

17 to correspond to behavioral differences between major and minor males, but little is

18 still known about the mating tactics of most rhinoceros beetle species. Future

19 studies on the relative benefits and performance of horns during male-male combat

20 are needed to fully understand the diversity of horn allometries and the evolution of

21 exaggerated structures.

22

23 Keywords: Dynastinae, horns, scaling, sexual selection 


\section{Introduction}

27 Variation in organismal shape is largely characterized by differences in the relative

28 size of body parts (Huxley, 1932; Thompson, 1942). That is, many of the gross

29 differences in body shape among diverse animal taxa are due to differences in the

30 proportional size of body structures (e.g., the enlarged beak of toucans, or the

31 elongated neck of giraffes). Within species, such shape differences are typically less

32 pronounced, because most traits scale proportionately with body size. A few traits,

33 however, increase in size much faster than overall body size, so large individuals are

34 not simply scaled-up versions of smaller ones. Nowhere are these patterns more

35 pronounced, or steep scaling relationships more apparent, than in the context of

36 sexually selected traits (Kodric-Brown, Sibly, \& Brown, 2006; Shingleton \&

37 Frankino, 2013).

38 Ornaments and weapons are typically much more variable than other non-

39 sexual structures (Alatalo, Hoglund, \& Lundberg, 1988; Cotton, Fowler, \&

40 Pomiankowski, 2004a; Emlen, Warren, Johns, Dworkin, \& Lavine, 2012; Fitzpatrick,

41 1997; Kawano, 2004; Pomiankowski \& Møller, 1995), and they almost always

42 exhibit positive allometries, or scaling relationships with slopes greater than 1

43 (Gould, 1973; Green, 1992; Kodric-Brown et al., 2006; Petrie, 1992; Simmons \&

44 Tomkins, 1996). Large individuals therefore have disproportionately larger

45 ornaments and weapons than small individuals, which results in extreme variation

46 in trait size and overall body form. Sexual selection is expected to favor the 
47 evolution of these steep scaling relationships for several reasons. First, ornaments

48 and weapons are typically used to signal a male's condition to potential mates or

49 competitors, and the costs and benefits of signaling are expected to be size-

50 dependent. That is, large males should benefit from producing large signals by

51 attracting more females or deterring rivals, while small males should gain very little

52 from advertising their small size and poor condition (Green, 1992; Petrie, 1992;

53 Simmons \& Tomkins, 1996). Second, because ornaments and weapons are often

54 expensive to produce and carry, only large, high-quality males are expected to be

55 capable of producing them (Andersson, 1982; Kodric-Brown \& Brown, 1984; Nur \&

56 Hasson, 1984; Zahavi, 1975). Third, because traits with steep scaling relationships

57 amplify differences in body size, these traits may be particularly informative signals

58 to choosy females and rival males in discerning otherwise subtle differences in a

59 male's overall size and condition (Cotton, Fowler, \& Pomiankowski, 2004b; Emlen et

60 al., 2012; Kodric-Brown et al., 2006; Maynard Smith \& Harper, 2003). Indeed,

61 theoretical models indicate that, as long as males with the smallest traits can

62 occasionally succeed at mating, sexual selection drives the evolution of ornaments

63 and weapons with strong positive allometry (Fromhage \& Kokko, 2014).

64 Although simple linear allometries have received the most attention in the

65 sexual selection literature, sexual traits can also exhibit more complex, non-linear

66 scaling relationships (Knell, 2009). In particular, sexual ornaments and weapons in

67 insects exhibit a variety of non-linear allometries, including curved, sigmoidal, and

68 discontinuous (Eberhard \& Gutierrez, 1991; Emlen \& Nijhout, 2000; Knell, Pomfret,

69 \& Tomkins, 2004; Knell, 2009; Nijhout \& Wheeler, 1996; Pomfret \& Knell, 2006). 
70 The shapes of scaling relationships are important for evolutionary biologists

71 because they offer clues about the selective pressures acting on these traits. For

72 example, the sigmoidal allometries of many horned dung beetles are likely to reflect

73 alternative adaptations for obtaining mating opportunities, with large, horned

74 "major" males specialized for fighting, and small, hornless "minor" males specialized

75 for sneaking (Eberhard \& Gutierrez, 1991; Emlen \& Nijhout, 2000; Emlen, 1997;

76 Moczek \& Emlen, 2000; Rasmussen, 1994), and the curved allometries of

77 exaggerated stag beetle mandibles may reflect a depletion of developmental

78 resources that ultimately limits mandible growth (Knell et al., 2004). Previous

79 authors have even suggested that the evolution of non-linear allometries should

80 favor the evolution of exaggerated structures (Emlen \& Nijhout, 2000), yet, to date,

81 little is known about how the shape of scaling relationships vary among closely

82 related species with different degrees of trait exaggeration.

83 Here, we present and analyze the most comprehensive survey to date on the

84 scaling relationships of rhinoceros beetle horns. Male rhinoceros beetles produce

85 long horns on their head and prothorax, and use them as weapons in male-male

86 battles over reproductive access to females (Beebe, 1944, 1947; Eberhard, 1977,

87 1980; Hongo, 2007; Siva-Jothy, 1987). Rhinoceros beetles exhibit a wide range of

88 both absolute and relative horn sizes (Enrödi, 1985; Mizunuma, 1999), which makes

89 them an ideal system for comparing the scaling relationships among species with

90 different degrees of horn exaggeration. We use our data to test for associations

91 between scaling relationship shape and among-species patterns of horn 
92 exaggeration, and discuss the factors that have influenced the shape of horn

93 allometries and the evolution of exaggerated structures.

94

\section{Materials and Methods}

96

97 We measured male specimens of nearly all horned Dynastinae species from

98 collections of the Smithsonian Institute and the University of Nebraska State

99 Museum. We focused on the scaling relationships of head horns because the head

100 horn is used to pry and dislodge opponents from contested resource sites (Beebe,

101 1944; Eberhard, 1980; Hongo, 2003; McCullough, Tobalske, \& Emlen, 2014), and

102 therefore is likely to be the primary target of sexual selection. All species with at

103 least 20 males were measured and analyzed, except for species belonging to the

104 genus Strategus, which have thoracic horns but no head horns.

105 Horn length and body size were measured to the nearest $0.01 \mathrm{~mm}$ with dial

106 calipers. We measured head horn length (hereafter simply referred to as horn

107 length, unless otherwise specified) as the straight-line distance from the clypeus to

108 the horn tip (Eberhard \& Gutierrez, 1991; Kawano, 1995; Knell et al., 2004), and

109 body size as pronotum width (see Emlen, 1997 for justification). Our results are

110 qualitatively the same if we used elytra length instead of prothorax width as the

111 measure of overall body size (unpublished data). Males with visible signs of injury

112 were measured, but only those with intact and undamaged horns were included in

113 the allometric analyses. Analyses were performed on log-transformed data. Our 
114 complete data set included measurements from 31 species, representing 16 genera

115 (Supplemental data).

116 Visual inspection of the log-log scatterplots suggested that the relationships

117 between horn length and body size were non-linear for nearly all species. We

118 therefore followed the recommendations of Knell (2009) to characterize possible

119 non-linear allometries. For each species, we compared five models on the basis of

120 their goodness of fit (using Akaike's information criterion, AIC) to determine which

121 model gave the best description of the relationship between horn length and body

122 size: i) a simple linear model, ii) a quadratic model, and iii) three different

123 breakpoint models of the form:

124

125 horn longth = body size $:$ morph

126

127 where morph is a factor distinguishing major and minor males. For the breakpoint

128 models, individuals were separated into the two morphs based on either a threshold

129 body size (following the procedure outlined in Eberhard \& Gutierrez, 1991) or a

130 threshold horn length (following the procedure outlined in Kotiaho \& Tomkins,

131 2001), or by examining a frequency histogram of the ratio between horn length and

132 body size to determine a threshold ratio (following the basic approach of Cook \&

133 Bean, 2006). We chose the model with the lowest AIC score as the best-fit allometric

134 model. Models with AIC scores that differ by less than 2 are considered to be

135 indistinguishable from each other in their explanatory power (Burnham \&

136 Anderson, 2002), but this was an issue for only two species. In both cases, the 
137 competing models were different breakpoint models, and thus equally

138 parsimonious, so we selected the model with the lowest AIC score.

139 We found that 30 of the 31 species had breakpoint allometries (Figure 1).

140 Further analyses were therefore conducted to explore the scaling relationships

141 between horn length and body size for the major and minor morphs. The remaining

142 species (Heterogomphus hirtus) had a quadratic allometry with a decreasing slope.

143 We include the raw morphometric data for this species in our supplemental data

144 file, but we excluded it from subsequent analyses on the dimorphic species.

145 We calculated the residuals from the least-squares regression of log median

146 horn length on log median body size as an index of horn exaggeration across species

147 (Figure 2; Knell et al., 2004; Simmons \& Tomkins, 1996). A positive residual

148 indicates that the species has a longer, or more exaggerated, horn than expected for

149 its body size, while a negative residual indicates that the species has a shorter, or

150 less exaggerated, horn than expected for its body size. We used median horn length

151 and body size rather than means because the median is more robust to outliers and

152 therefore less likely to be affected by potential collection biases for very large males

153 (Knell et al., 2004).

154 Because most species have both a head horn and a thoracic horn, we also

155 calculated a composite measure of horn exaggeration (i.e., an index of total horn

156 investment) by adding the lengths of the head horn and thoracic horn. (In

157 Chalcosoma atlas and Coelosis bicornis, we calculated total horn investment by

158 adding head horn length and twice the thoracic horn length, because males have a 
159 pair of thoracic horns.) Thoracic horn length was measured as the straight-line

160 distance from the base of the pronotum to the horn tip.

161 We examined the relationships between horn exaggeration, total horn

162 investment, and allometric slopes using general linear models. As yet, there is no

163 complete phylogeny for the Dynastinae, so we were unable to use robust

164 comparative analyses that take into account tree topologies and branch lengths. We

165 therefore used taxonomy to account for shared evolutionary history, which is

166 preferable to ignoring evolutionary history altogether (Freckleton, 2009; Sunday,

167 Bates, \& Dulvy, 2011). Specifically, we controlled for the non-independence of the

168 data due to phylogenetic relatedness by using linear mixed effects models with

169 Genus as a nested random effect using the Ime function in R (Blackburn \& Duncan,

170 2001; Sodhi et al., 2008; Sunday et al., 2011; Woods \& Smith, 2010).

\section{Results}

173

174 Nearly all of the rhinoceros beetles that we measured and analyzed were male

175 dimorphic; 30 of the 31 species had a discontinuous, breakpoint allometry, with

176 different lines describing the relationship between horn length and body size for

177 major and minor morphs (Figure 1). The two morphs overlapped considerably in

178 both horn length and body size in most species (22 species, $73 \%$ ), so the morphs

179 were best separated by calculating the ratio of horn length to body size. Of the

180 remaining species, there were seven $(23 \%)$ in which the two morphs were best

181 separated by a threshold horn length, and one (3\%) in which the two morphs were 
182 best separated by a threshold body size.

183 Table 1 reports the median horn length, median body size, and horn

184 allometry of major and minor males for all dimorphic species. There was a

185 significant positive relationship between residual horn length and median head

186 horn length among species $\left(\mathrm{R}^{2}=0.27, \mathrm{~F}_{1,28}=10.24, \mathrm{p}<0.001\right)$, indicating that

187 species with relatively longer horns also had absolutely longer horns. There was

188 also a significant positive relationship between residual horn length and total

189 investment in horns $\left(\mathrm{R}^{2}=0.43, \mathrm{~F}_{2,20}=7.54, \mathrm{p}<0.001\right.$; with prothorax width

190 included as a covariate to remove the effect of body size), which is attributed, at

191 least in part, to the positive correlation between median head horn length and

192 median thoracic horn length $\left(R^{2}=0.39, F_{1,21}=13.59, p=0.001\right)$. These results

193 indicate that males do not invest in head horns at the expense of thoracic horns (or

194 vice versa).

195 The allometric slopes were significantly steeper for minor males than for

196 major males $\left(\mathrm{T}_{29}=3.56, \mathrm{p}=0.001\right)$. The average slope was $2.32 \pm 0.98($ mean $\pm \mathrm{sd})$

197 for minor males and $1.46 \pm 0.56$ for major males. Both morphs had allometric slopes

198 that were significantly greater than 1 (minor males: $\mathrm{T}_{29}=7.36, \mathrm{p}<0.001$; major

199 males: $\mathrm{T}_{29}=6.59, \mathrm{p}<0.001$ ). There was a significant positive relationship between

200 the allometric slope of minor males and residual horn length (Figure 3; $\mathrm{R}^{2}=0.25$,

$201 \quad F_{1,28}=9.18, p<0.01$ ), but there was no relationship between the allometric slope of

202 major males and residual horn length (Figure $3 ; \mathrm{R}^{2}=0.01, \mathrm{~F}_{1,28}=0.22, \mathrm{p}=0.64$ ).

203 These results indicate that minor males exhibit steeper scaling relationships in

204 species with more exaggerated horns. There was also a significant positive 
205 relationship between residual horn length and the difference in slopes between

206 minor and major males (Figure $4 ; \mathrm{R}^{2}=0.38, \mathrm{~F}_{1,28}=17.28, \mathrm{p}<0.001$ ), indicating that

207 species with more exaggerated horns exhibit a greater decrease in allometric slope

208 between minor and major males. This relationship remained significant even after

209 controlling for phylogenetic relatedness $\left(\mathrm{T}_{14}=4.26, \mathrm{p}<0.001\right)$.

210 Many specimens showed signs of injury from fights, including scratches and

211 punctures on their elytra or pronota, and chipped or broken horns. On average, $7 \%$

212 (maximum $=17 \%$ ) of the specimens for a given species showed some sign of injury,

213 and 3\% (maximum $=9 \%$ ) of the specimens had broken horns. There was a weak,

214 positive relationship among species between residual horn length and the frequency

215 of injuries $\left(R^{2}=0.09, F_{1,28}=3.72, p=0.06\right)$, suggesting that species with more

216 exaggerated horns suffer higher rates of damage from fights.

\section{Discussion}

220 We found strong evidence for male dimorphism in the rhinoceros beetles. Nearly all

221 of the species surveyed had discontinuous, breakpoint allometries, indicating the

222 presence of two male morphs. The two morphs, however, were relatively cryptic

223 (sensu J. M. Cook \& Bean, 2006), because there was substantial overlap in both horn

224 length and body size. These results contrast with the patterns observed in horned

225 dung beetles and other dimorphic insects in which males transition from having no

226 horns to fully-sized horns over a narrow range of body size (D. Cook, 1987;

227 Eberhard \& Gutierrez, 1991; Emlen, 1997; Moczek, 1998). Previous authors have 
228 argued that the ability to developmentally switch from minimal to maximal trait

229 expression may have facilitated the evolution of exaggerated morphologies by

230 uncoupling the phenotypes of large and small individuals, thereby allowing the two

231 size classes to evolve relatively independently (Emlen \& Nijhout, 2000; West-

232 Eberhard, 1989, 1992). Our data do not support this hypothesis. Despite the

233 impressive size of rhinoceros beetle horns, there were no species that transitioned

234 abruptly from minimal to complete horn expression, which indicates that the

235 developmental capacity to prevent horn growth in small individuals is not necessary

236 for the evolution of exaggerated morphologies.

237 Male dimorphisms are common among insects, and are typically associated

238 with alternative reproductive tactics (Gross, 1996; Oliveira, Taborsky, \&

239 Brockmann, 2008). For example, in many horned dung beetles, large "major" males

240 use their horns as weapons to guard the entrances of tunnels and fight with rival

241 males over access to females, while small hornless "minor" males rely on sneaking

242 behaviors to gain matings inside the tunnels guarded by larger males (D. Cook,

243 1987; Emlen, 1997; Moczek \& Emlen, 2000; Rasmussen, 1994). Unfortunately, very

244 few rhinoceros beetle species have been studied rigorously in the field, so it is

245 largely unknown whether the two morphs identified by our allometric analyses

246 employ different tactics to gain matings. In the South American rhinoceros beetle

247 Podischnus agenor, there is evidence that minor males emerge earlier in the season

248 and have a greater tendency to disperse than major males, which may represent a

249 non-aggressive satellite tactic to reduce the probability of direct combat with major

250 males (Eberhard, 1982). However, in the Asian rhinoceros beetle Trypoxylus 
251 dichotomus, there are no apparent differences in behavior between morphs: both

252 minor and major males use their horns to fight with rivals, and both have been

253 found using sneaking behaviors (Hongo, 2003, 2007). These observations highlight

254 the need for more behavioral studies on natural populations of rhinoceros beetles,

255 because discrete morphological morphs do not necessarily correspond to discrete

256 behavioral morphs (Knell, 2009).

257 Both major and minor males showed steep positive allometries, and there

258 was a positive correlation between the allometric slope of minor males and residual

259 horn length. These results are consistent with the patterns found in the scaling

260 relationships of earwig forceps and stalk-eyed fly eye-spans, in which species with

261 the most intense sexual selection also have the steepest allometric slopes (Baker \&

262 Wilkinson, 2001; Simmons \& Tomkins, 1996). Although we recognize that not all

263 traits exhibiting positive allometries are sexually selected, and not all sexually-

264 selected traits are positively allometric (Bonduriansky, 2007), we expect sexual

265 selection to be the primary force driving the positive allometry of rhinoceros beetle

266 horns. Theoretical models predict sexual selection to favor the evolution of traits

267 with particularly steep allometries when male-male competition is intense, and trait

268 differences decisively determine the outcomes of competitive interactions

269 (Fromhage \& Kokko, 2014). These conditions are characteristic of rhinoceros beetle

270 mating systems; in all species studied to date, horns are used exclusively in the

271 context of intense male-male battles, horn length is the determining factor in the

272 outcome of fights, and males with the longest horns win (Beebe, 1944; Eberhard,

273 1980; Hongo, 2003, 2007; Karino, Niiyama, \& Chiba, 2005; Siva-Jothy, 1987). 
275 allometric slope of minor males, there was no relationship between residual horn

276 length and the allometric slope of major males. Major males generally had shallower

277 slopes than minor males, and the difference in slope depended on residual horn

278 length: species with relatively long horns showed a greater decrease in slope

279 between major and minor males than did species with relatively short horns. These

280 patterns mirror the curved allometries of stag beetle mandibles (Huxley, 1932; Knell

281 et al., 2004) and the tapered allometries of giraffe weevil rostra (Painting \& Holwell,

282 2013), and suggest that asymptotes in maximum trait size are common among

283 beetles and other holometabolous insects with exaggerated weapons.

284 We predict that the decline in slope from minor to major males reflects a

285 limitation in resource allocation during horn growth (Knell et al., 2004; Nijhout \&

286 Wheeler, 1996; Tomkins, Kotiaho, \& LeBas, 2005a). Because beetle horns develop

287 from a finite resource pool after the larva has stopped feeding, the growth of very

288 large horns may locally deplete developmental resources, and thereby limit further

289 allometric growth (Knell et al., 2004; Tomkins et al., 2005a). In particular, large

290 individuals of species with relatively long horns are the most likely to suffer from

291 resource allocation constraints, which helps explain why the decline in allometric

292 slopes between major and minor males is greatest among species with the largest

293 residual horn lengths, and thus the most exaggerated horns (Knell et al., 2004).

294 There are at least three alternative explanations that could also account for

295 the decline in slope between major and minor males. First, the fitness gain from

296 greater investment in horns may decrease with body size. For example, if major 
297 males already have a competitive advantage over most males in the population due

298 to their large size, they may not face strong selection to invest further in horn

299 growth (Painting \& Holwell, 2013). Future studies should therefore measure the

300 relative benefits of horn investment across the full range of male body size to

301 examine how different fitness functions may affect the shape of horn allometries

302 (Bonduriansky \& Day, 2003; Pomfret \& Knell, 2006).

303 Second, resource allocation tradeoffs with other fitness-enhancing traits may

304 prevent major males from investing more in horns. Previous studies on armed

305 insects have shown that the development of exaggerated weapons often comes at a

306 cost to the development of other body parts, such as eyes, wings, or testes (Emlen,

307 2001; Nijhout \& Emlen, 1998; Simmons \& Emlen, 2006; Yamane, Okada, Nakayama,

308 \& Miyatake, 2010), so strong selection on a male's ability to see, fly, or invest heavily

309 in sperm may constrain the further exaggeration of horns (Emlen, 2001; Yamane et

310 al., 2010).

311 Third, increasingly larger horns may be prohibitively costly if males cannot

312 also invest more in compensatory or supportive traits. Sexually-selected weapons

313 are often accompanied by changes in morphology and physiology that either

314 mitigate the costs of bearing these structures (Husak \& Swallow, 2011; Oufiero \&

315 Garland, 2007), or enhance a male's ability to use them in male-male combat (Okada

316 \& Miyatake, 2009; Tomkins, Kotiaho, \& LeBas, 2005b). For example, male stalk-eyed

317 flies have larger wings and thoraces than females, which may offset the costs of

318 flying with their exaggerated eye-spans (Husak, Ribak, Wilkinson, \& Swallow, 2011;

319 Ribak \& Swallow, 2007; Swallow, Wilkinson, \& Marden, 2000), and male earwigs 
320 with relatively large forceps also have relatively large hind-legs, which presumably

321 helps them wield the weapons and improves their fighting success (Tomkins et al.,

322 2005b). Because selection should favor individuals that can use, display, and bear

323 their weapons most effectively, male rhinoceros beetles may not benefit from

324 developing larger horns unless there are commensurate changes in their integrated 325 body plan.

326 There was a significant correlation between investment in head horns and

327 thoracic horns, and the scaling relationships of thoracic horns were very similar to

328 those of head horns (unpublished data). These observations suggest that head and

329 thoracic horns are developmentally coupled, but further work is needed to

330 determine whether this link is due to the same genetic mechanism for horn growth,

331 or similar selection on head and thoracic horns as an integrated fighting structure

332 (Okada \& Miyatake, 2009; Tomkins et al., 2005b). However, species also differ in the

333 number and location of thoracic horns (e.g., thoracic horns can develop from the

334 front, middle, or sides of the pronotum), and future studies should examine whether

335 these differences contribute to the variation in the size and scaling relationships of

336 head horns among species. For example, if multiple thoracic horns constrain the

337 development of wings and other neighboring body parts (Emlen, 2001; Kawano,

338 1995; Nijhout \& Emlen, 1998), then species that must fly long distances for food or

339 mates may be selected to invest less in thoracic horns (Emlen, 2001), and

340 concomitantly may invest less in head horns.

341 Finally, we note that this study only examined variation in horn length, even

342 though species also vary dramatically in horn shape. Interspecific differences in 
343 horn morphology are likely to reflect structural adaptations to species-specific

344 fighting styles (McCullough et al., 2014), but little is known about how horn

345 morphology varies within species across the range of body size, and whether these

346 changes also reflect structural adaptations to meet the mechanical demands of

347 fighting. We recently found that in the Asian rhinoceros beetle Trypoxylus

348 dichotomus, the second moment of area of horns (a measure of cross-sectional

349 shape) increased with horn length in such a way that preserved the horns'

350 performance as a stiff and strong weapon (McCullough, Ledger, \& Moore, 2015).

351 However, these relationships may differ among species depending on the style and

352 intensity of fights (Kitchener, 1985, 1991; McCullough et al., 2015; McCullough,

353 2014). Studies that compare the mechanical demands and performance of horns

354 within and among species will be important for understanding the variation in

355 scaling relationships of rhinoceros beetle horns and other animal weapons.

357 References

358

359 Alatalo, R. V., Hoglund, J., \& Lundberg, A. (1988). Patterns of variation in tail

$360 \quad$ ornament size in birds. Biological Journal of the Linnean Society, 34(4), 363-

361 374. http://doi.org/10.1111/j.1095-8312.1988.tb01969.x

362 Andersson, M. (1982). Sexual selection, natural selection and quality advertisement.

363 Biological Journal of the Linnean Society, 17(4), 375-393.

$364 \quad$ http://doi.org/10.1111/j.1095-8312.1982.tb02028.x 
365 Baker, R. H., \& Wilkinson, G. S. (2001). Phylogenetic analysis of sexual dimorphism and eye-span allometry in stalk-eyed flies (Diopsidae). Evolution, 55(7), 1373-1385. http://doi.org/10.1111/j.0014-3820.2001.tb00659.x

368 Beebe, W. (1944). The function of secondary sexual characters in two species of 369 Dynastinae (Coleoptera). Zoologica, 29, 53-58.

370 Beebe, W. (1947). Notes on the Hercules Beetle, Dynastes hercules (Linn.), at Rancho 371 Grande, Venezuela, with special reference to combat behavior. Zoologica, 32, 372 109-116.

373 Blackburn, T. M., \& Duncan, R. P. (2001). Determinants of establishment success in 374 375 introduced birds. Nature, 414(6860), 195-197. http://doi.org/10.1038/35102557

Bonduriansky, R. (2007). Sexual selection and allometry: a critical reappraisal of the evidence and ideas. Evolution, 61(4), 838-849. http://doi.org/10.1111/j.1558-5646.2007.00081.x

379 Bonduriansky, R., \& Day, T. (2003). The evolution of static allometry in sexually $380 \quad$ selected traits. Evolution, 57(11), 2450-2458. http://doi.org/10.1111/j.0014-3820.2003.tb01490.x

382 Burnham, K. P., \& Anderson, D. R. (2002). Model Selection and Multimodel Inference: 383 A Practical Information-Theoretic Approach (2nd ed.). New York: Springer. 384 Cook, D. (1987). Sexual selection in dung beetles I. A multivariate study of the 385 morphological variation in 2 species of Onthophagus (Scarabaeidae, 386 Onthophagini). Australian Journal of Zoology, 35(2), 123-132. 
387 Cook, J. M., \& Bean, D. (2006). Cryptic male dimorphism and fighting in a fig wasp.

388 Animal Behaviour, 71(5), 1095-1101.

389 http://doi.org/10.1016/j.anbehav.2005.07.027

390 Cotton, S., Fowler, K., \& Pomiankowski, A. (2004a). Condition dependence of sexual

391 ornament size and variation in the stalk-eyed fly $<\mathrm{i}>$ Cyrtodiopsis

392 dalmanni</I> (Diptera: Diopsidae). Evolution, 58(5), 1038-1046.

$393 \quad$ http://doi.org/10.1111/j.0014-3820.2004.tb00437.x

394 Cotton, S., Fowler, K., \& Pomiankowski, A. (2004b). Do sexual ornaments

395 demonstrate heightened condition-dependent expression as predicted by the

396 handicap hypothesis? Proceedings of the Royal Society B: Biological Sciences,

397 271(1541), 771-783. http://doi.org/10.1098/rspb.2004.2688

398 Eberhard, W. G. (1977). Fighting behavior of male Golofa porteri (Scarabeidae:

399 Dynastinae). Psyche, 84, 292-298.

400 Eberhard, W. G. (1980). Horned beetles. Scientific American, 242, 166-182.

401 Eberhard, W. G. (1982). Beetle horn dimorphism: making the best of a bad lot.

$402 \quad$ American Naturalist, 119(3), 420-426.

403 Eberhard, W. G., \& Gutierrez, E. E. (1991). Male dimorphisms in beetles and earwigs

404 and the question of developmental constraints. Evolution, 45(1), 18-28.

405 Emlen, D. J. (1997). Alternative reproductive tactics and male-dimorphism in the

406 horned beetle Onthophagus acuminatus (Coleoptera: Scarabaeidae).

407 Behavioral Ecology and Sociobiology, 41(5), 335-341.

$408 \quad$ http://doi.org/10.1007/s002650050393 
409 Emlen, D. J. (2001). Costs and the diversification of exaggerated animal structures.

$410 \quad$ Science, 291(5508), 1534 -1536. http://doi.org/10.1126/science.1056607

411 Emlen, D. J., \& Nijhout, H. F. (2000). The development and evolution of exaggerated 412 morphologies in insects. Annual Review of Entomology, 45(1), 661-708. 413 http://doi.org/10.1146/annurev.ento.45.1.661

414 Emlen, D. J., Warren, I. A., Johns, A., Dworkin, I., \& Lavine, L. C. (2012). A mechanism 415 of extreme growth and reliable signaling in sexually selected ornaments and 416 weapons. Science, 337(6096), 860-864. http://doi.org/10.1126/science.1224286

418 Enrödi, S. (1985). The Dynastinae of the World. The Hague, Netherlands: Dr. W. Junk. 419 Fitzpatrick, S. (1997). Patterns of morphometric variation in birds' tails: length, 420 421

422 Freckleton, R. P. (2009). The seven deadly sins of comparative analysis. Journal of 423 Evolutionary Biology, 22(7), 1367-1375. http://doi.org/10.1111/j.1420424 9101.2009.01757.x

425 Fromhage, L., \& Kokko, H. (2014). Sexually selected traits evolve positive allometry 426 when some matings occur irrespective of the trait. Evolution, 68(5), 13321338. http://doi.org/10.1111/evo.12349

428 Gould, S. J. (1973). Positive allometry of antlers in the "Irish Elk", Megaloceros giganteus. Nature, 244(5415), 375-376. http://doi.org/10.1038/244375a0

430 Green, A. J. (1992). Positive allometry is likely with mate choice, competitive display 431 and other functions. Anim. Behav, 43(1), 170-172. 
432 Gross, M. G. (1996). Alternative reproductive strategies and tactics: diversity within

433

434

435

436

437

438

439

440

441

442

443

444

445

446

447

448 Huxley, J. S. (1932). Problems of Relative Growth. London: Methuen.

449 Karino, K., Niiyama, H., \& Chiba, M. (2005). Horn length is the determining factor in

450 the outcomes of escalated fights among male Japanese horned beetles,

$451 \quad$ Allomyrina dichotoma L. (Coleoptera: Scarabaeidae). Journal of Insect

452 sexes. Trends in Ecology \& Evolution, 11(2), 92-98. http://doi.org/10.1016/0169-5347(96)81050-0

Hongo, Y. (2003). Appraising behaviour during male-male interaction in the Japanese horned beetle Trypoxylus dichotomus septentrionalis (Kono). Behaviour, 140(4), 501-517. http://doi.org/10.1163/156853903322127959

Hongo, Y. (2007). Evolution of male dimorphic allometry in a population of the Japanese horned beetle Trypoxylus dichotomus septentrionalis. Behavioral Ecology and Sociobiology, 62(2), 245-253. http://doi.org/10.1007/s00265007-0459-2

Husak, J. F., Ribak, G., Wilkinson, G. S., \& Swallow, J. G. (2011). Compensation for exaggerated eye stalks in stalk-eyed flies (Diopsidae). Functional Ecology, 25(3), 608-616. http://doi.org/10.1111/j.1365-2435.2010.01827.x

Husak, J. F., \& Swallow, J. G. (2011). Compensatory traits and the evolution of male ornaments. Behaviour, 148(1), 1-29. http://doi.org/10.1163/000579510X541265 Behavior, 18(6), 805-815. http://doi.org/10.1007/s10905-005-8741-5 
453 Kawano, K. (1995). Horn and wing allometry and male dimorphism in giant

454 rhinoceros beetles (Coleoptera: Scarabaeidae) of tropical Asia and America.

455 Annals of the Entomological Society of America, 88(1), 92-99.

456 Kawano, K. (2004). Developmental stability and adaptive variability of male

457 genitalia in sexually dimorphic beetles. American Naturalist, 163(1), 1-15.

458 Kitchener, A. (1985). The effect of behaviour and body weight on the mechanical

459 design of horns. Journal of Zoology, 205(2), 191-203.

$460 \quad$ http://doi.org/10.1111/j.1469-7998.1985.tb03528.x

461 Kitchener, A. (1991). The evolution and mechanical design of horns and antlers. In

462 Biomechanics in Evolution (pp. 229-253). Cambridge: Cambridge University

$463 \quad$ Press.

464 Knell, R. J. (2009). On the analysis of non-linear allometries. Ecological Entomology,

465 34(1), 1-11. http://doi.org/10.1111/j.1365-2311.2008.01022.x

466 Knell, R. J., Pomfret, J. C., \& Tomkins, J. L. (2004). The limits of elaboration: curved

467 allometries reveal the constraints on mandible size in stag beetles.

$468 \quad$ Proceedings of the Royal Society B: Biological Sciences, 271(1538), 523-528.

$469 \quad$ http://doi.org/10.1098/rspb.2003.2641

470 Kodric-Brown, A., \& Brown, J. H. (1984). Truth in advertising: the kinds of traits

471 favored by sexual selection. American Naturalist, 124(3), 309-323.

472 Kodric-Brown, A., Sibly, R. M., \& Brown, J. H. (2006). The allometry of ornaments and

$473 \quad$ weapons. Proceedings of the National Academy of Sciences, 103(23), 8733-

474 8738. http://doi.org/10.1073/pnas.0602994103 
475 Kotiaho, J. S., \& Tomkins, J. L. (2001). The discrimination of alternative male 476 morphologies. Behavioral Ecology, 12(5), 553 -557.

477 Maynard Smith, J., \& Harper, D. (2003). Animal signals. Oxford: Oxford University $478 \quad$ Press.

479 McCullough, E. L. (2014). Mechanical limits to maximum weapon size in a giant $480 \quad$ rhinoceros beetle. Proceedings of the Royal Society B: Biological Sciences, 281, 481 20140696. http://doi.org/10.1098/rspb.2014.0696

482 McCullough, E. L., Ledger, K. J., \& Moore, T. Y. (2015). Variation in cross-sectional 483 horn shape within and among rhinoceros beetle species. Biological Journal of 484 the Linnean Society, 115, 810-817. http://doi.org/10.1111/bij.12557

485 McCullough, E. L., Tobalske, B. W., \& Emlen, D. J. (2014). Structural adaptations to 486 diverse fighting styles in sexually selected weapons. Proceedings of the $487 \quad$ National Academy of Sciences, 111(40), 14484-14488.

488 http://doi.org/10.1073/pnas.1409585111

489 Mizunuma, T. (1999). Giant Beetles. Tokyo: ESI Publishers.

490 Moczek, A. P. (1998). Horn polyphenism in the beetle Onthophagus taurus: larval 491 diet quality and plasticity in parental investment determine adult body size 492 and male horn morphology. Behavioral Ecology, 9(6), 636-641.

$493 \quad$ http://doi.org/10.1093/beheco/9.6.636

494 Moczek, A. P., \& Emlen, D. J. (2000). Male horn dimorphism in the scarab beetle, 495 Onthophagus taurus: do alternative reproductive tactics favour alternative 496 phenotypes? Animal Behaviour, 59(2), 459-466.

497 http://doi.org/10.1006/anbe.1999.1342 
498 Nijhout, H. F., \& Emlen, D. J. (1998). Competition among body parts in the

499 development and evolution of insect morphology. Proceedings of the National

$500 \quad$ Academy of Sciences, 95(7), $3685-3689$.

501 Nijhout, H. F., \& Wheeler, D. E. (1996). Growth models of complex allometries in

502 holometabolous insects. American Naturalist, 148(1), 40-56.

503 Nur, N., \& Hasson, O. (1984). Phenotypic plasticity and the handicap principle.

$504 \quad$ Journal of Theoretical Biology, 110(2), 275-297.

$505 \quad$ http://doi.org/10.1016/S0022-5193(84)80059-4

506 Okada, K., \& Miyatake, T. (2009). Genetic correlations between weapons, body shape

507 and fighting behaviour in the horned beetle Gnatocerus cornutus. Animal

$508 \quad$ Behaviour, 77(5), 1057-1065.

509 http://doi.org/10.1016/j.anbehav.2009.01.008

510 Oliveira, R. F., Taborsky, M., \& Brockmann, H. J. (2008). Alternative Reproductive

511 Tactics: an Integrative Approach. Cambridge: Cambridge University Press.

512 Oufiero, C. E., \& Garland, T. (2007). Evaluating performance costs of sexually

$513 \quad$ selected traits. Functional Ecology, 21(4), 676-689.

$514 \quad$ http://doi.org/10.1111/j.1365-2435.2007.01259.x

515 Painting, C. J., \& Holwell, G. I. (2013). Exaggerated trait allometry, compensation and

516 trade-offs in the New Zealand giraffe weevil (Lasiorhynchus barbicornis).

$517 \quad$ PLoS ONE, 8(11), e82467. http://doi.org/10.1371/journal.pone.0082467

518 Petrie, M. (1992). Are all secondary sexual display structures positively allometric

519 and, if so, why? Animal Behaviour, 43, 173-175. 
520 Pomfret, J. C., \& Knell, R. J. (2006). Sexual selection and horn allometry in the dung

521 beetle Euoniticellus intermedius. Animal Behaviour, 71(3), 567-576.

$522 \quad$ http://doi.org/10.1016/j.anbehav.2005.05.023

523 Pomiankowski, A., \& Møller, A. P. (1995). A resolution of the lek paradox.

$524 \quad$ Proceedings of the Royal Society B, 260, 21-29.

525 Rasmussen, J. L. (1994). The influence of horn and body size on the reproductive

526 behavior of the horned rainbow scarab beetle Phanaeus difformis

527 (Coleoptera: Scarabaeidae). Journal of Insect Behavior, 7(1), 67-82.

$528 \quad$ http://doi.org/10.1007/BF01989828

529 Ribak, G., \& Swallow, J. (2007). Free flight maneuvers of stalk-eyed flies: do eye-

530 stalks affect aerial turning behavior? Journal of Comparative Physiology A:

$531 \quad$ Neuroethology, Sensory, Neural, and Behavioral Physiology, 193(10), 1065-

532 1079. http://doi.org/10.1007/s00359-007-0259-1

533 Shingleton, A. W., \& Frankino, W. A. (2013). New perspectives on the evolution of

$534 \quad$ exaggerated traits. BioEssays: News and Reviews in Molecular, Cellular and

535 Developmental Biology, 35(2), 100-107.

536 http://doi.org/10.1002/bies.201200139

537 Simmons, L. W., \& Emlen, D. J. (2006). Evolutionary trade-off between weapons and

538 testes. Proceedings of the National Academy of Sciences, 103(44), 16346 -

$539 \quad 16351$.

540 Simmons, L. W., \& Tomkins, J. L. (1996). Sexual selection and the allometry of earwig 541 forceps. Evolutionary Ecology, 10(1), 97-104.

$542 \quad$ http://doi.org/10.1007/BF01239350 
543 Siva-Jothy, M. (1987). Mate securing tactics and the cost of fighting in the Japanese

544 horned beetle, Allomyrina dichotoma L. (Scarabaeidae). Journal of Ethology,

$545 \quad$ 5(2), 165-172. http://doi.org/10.1007/BF02349949

546 Sodhi, N. S., Bickford, D., Diesmos, A. C., Lee, T. M., Koh, L. P., Brook, B. W., ...

547 Bradshaw, C. J. A. (2008). Measuring the meltdown: drivers of global

$548 \quad$ amphibian extinction and decline. PLOS ONE, 3(2), e1636.

549 http://doi.org/10.1371/journal.pone.0001636

550 Sunday, J. M., Bates, A. E., \& Dulvy, N. K. (2011). Global analysis of thermal tolerance

551 and latitude in ectotherms. Proceedings of the Royal Society of London B,

552 278(1713), 1823-1830. http://doi.org/10.1098/rspb.2010.1295

553 Swallow, J. G., Wilkinson, G. S., \& Marden, J. H. (2000). Aerial performance of stalk-

$554 \quad$ eyed flies that differ in eye span. Journal of Comparative Physiology B:

555 Biochemical, Systemic, and Environmental Physiology, 170(7), 481-487.

$556 \quad$ http://doi.org/10.1007/s003600000124

557 Thompson, D. W. (1942). On Growth and Form. Cambridge, UK: Cambridge

$558 \quad$ University Press.

559 Tomkins, J. L., Kotiaho, J. S., \& LeBas, N. R. (2005a). Matters of scale: positive

560 allometry and the evolution of male dimorphisms. American Naturalist,

$561 \quad$ 165(3), 389-402. http://doi.org/10.1086/427732

562 Tomkins, J. L., Kotiaho, J. S., \& LeBas, N. R. (2005b). Phenotypic plasticity in the

563 developmental integration of morphological trade-offs and secondary sexual

564 trait compensation. Proceedings of the Royal Society B: Biological Sciences,

565 272(1562), $543-551$. http://doi.org/10.1098/rspb.2004.2950 
566 West-Eberhard, M. J. (1989). Phenotypic plasticity and the origins of diversity.

567 Annual Review of Ecology, Evolution, and Systematics, 20, 249-278.

568 West-Eberhard, M. J. (1992). Behavior and evolution. In Molds, Molecules, and

569 Metazoa: Growing Points in Evolutionary Biology. Princeton, NJ: Princeton

$570 \quad$ University Press.

571 Woods, H. A., \& Smith, J. N. (2010). Universal model for water costs of gas exchange

572 by animals and plants. Proceedings of the National Academy of Sciences,

$573 \quad 107(18), 8469-8474$.

574 Yamane, T., Okada, K., Nakayama, S., \& Miyatake, T. (2010). Dispersal and

575 ejaculatory strategies associated with exaggeration of weapon in an armed

$576 \quad$ beetle. Proceedings of the Royal Society of London B: Biological Sciences.

$577 \quad$ http://doi.org/10.1098/rspb.2009.2017

578 Zahavi, A. (1975). Mate selection: selection for a handicap. Journal of Theoretical

579 Biology, 53(1), 205-214. http://doi.org/10.1016/0022-5193(75)90111-3

580

581

582

583

584

585

586

587

588 
589 Table 1. Sample size, median body size (in millimeters), median horn length (in 590 millimeters), allometric slope of minor males, and allometric slope of major males of 591 all dimorphic rhinoceros beetle species included in the study

592

\begin{tabular}{l|c|c|c|c|c}
\hline \multicolumn{1}{c|}{ Species } & $\mathbf{N}$ & $\begin{array}{c}\text { Body } \\
\text { size }\end{array}$ & $\begin{array}{c}\text { Horn } \\
\text { length }\end{array}$ & $\begin{array}{c}\text { Minor } \\
\text { slope }\end{array}$ & $\begin{array}{c}\text { Major } \\
\text { slope }\end{array}$ \\
\hline Augosoma centaurus & 83 & 25.29 & 27.57 & 3.18 & 1.50 \\
\hline Chalcosoma atlas & 42 & 24.93 & 21.02 & 1.95 & 0.51 \\
\hline Coelosis bicornis & 44 & 13.61 & 10.48 & 1.50 & 0.91 \\
\hline Diloboderus abderus & 106 & 12.13 & 12.37 & 2.66 & 1.33 \\
\hline Dynastes granti & 158 & 18.05 & 13.54 & 1.99 & 1.76 \\
\hline Dynastes hercules & 71 & 30.63 & 38.63 & 3.45 & 2.24 \\
\hline Dynastes tityus & 172 & 19.79 & 12.53 & 1.23 & 1.66 \\
\hline Enema pan & 95 & 24.97 & 22.82 & 0.90 & 1.25 \\
\hline Golofa costaricensis & 63 & 15.08 & 11.54 & 3.56 & 2.40 \\
\hline Golofa eacus & 58 & 14.28 & 12.13 & 3.07 & 2.26 \\
\hline Golofa imperialis & 22 & 13.84 & 8.41 & 2.55 & 2.79 \\
\hline Golofa pelagon & 34 & 12.55 & 7.57 & 1.74 & 2.65 \\
\hline Golofa pizarro & 70 & 15.62 & 15.22 & 3.38 & 1.57 \\
\hline Golofa tersander & 24 & 12.71 & 11.83 & 4.67 & 2.09 \\
\hline Hetergomphus chevrolati & 94 & 21.91 & 11.36 & 2.50 & 1.57 \\
\hline Hetergomphus schoenherri & 68 & 18.06 & 10.06 & 1.72 & 1.25 \\
\hline Megasoma elephas & 35 & 37.79 & 33.87 & 1.45 & 1.76 \\
\hline Megasoma pachecoi & 144 & 15.83 & 10.47 & 2.71 & 1.83 \\
\hline Megasoma thersites & 38 & 15.46 & 9.16 & 0.95 & 1.33 \\
\hline Oryctes boas & 47 & 16.87 & 14.14 & 3.79 & 2.07 \\
\hline Oryctes nasicornis & 59 & 13.73 & 8.40 & 3.33 & 1.79 \\
\hline Oryctes rhinoceros & 70 & 17.43 & 9.27 & 2.41 & 1.82 \\
\hline Podischnus agenor & 68 & 15.84 & 10.36 & 3.31 & 2.02 \\
\hline Podischnus oberthueri & 29 & 16.17 & 10.40 & 1.78 & 1.45 \\
\hline Spodistes mniszechi & 40 & 11.62 & 7.01 & 2.00 & 2.49 \\
\hline Trypoxylus dichotomus & 49 & 23.62 & 25.55 & 1.73 & 0.96 \\
\hline Xyloryctes ensifer & 25 & 17.36 & 9.18 & 0.97 & 1.20 \\
\hline Xyloryctes jamaicensis & 73 & 14.82 & 8.58 & 0.80 & 0.79 \\
\hline Xylotrupes gideon & 480 & 17.43 & 11.00 & 1.82 & 1.72 \\
\hline Xylotrupes pubescens & 36 & 18.08 & 10.64 & 2.39 & 1.14 \\
& & & & & \\
\hline & & & & & \\
\hline
\end{tabular}

593

594

595

596

597 


\section{FIGURE LEGENDS}

599

600 Figure 1. Variation in the allometric relationships between horn length and body

601 size among the 30 dimorphic species. Closed circles represent major males, and

602 open circles represent minor males.

603

604 Figure 2. Interspecific relationship between median horn length and median

605 pronotum width $\left(\mathrm{R}^{2}=0.72, \mathrm{~F}_{1,28}=76.6, \mathrm{p}<0.001\right)$. Insets show examples of species

606 with a positive residual horn length (i.e., high degree of horn exaggeration, Dynastes

607 hercules) and a negative residual horn length (i.e., low degree of horn exaggeration,

608 Heterogomphus chevrolati).

609

610 Figure 3. Relationships between residual horn length and allometric slope for

611 minor males (top: $\mathrm{R}^{2}=0.25, \mathrm{~F}_{1,28}=9.18, \mathrm{P}<0.01$ ) and major males (bottom: $\mathrm{R}^{2}=$

$\left.6120.01, \mathrm{~F}_{1,28}=0.22, \mathrm{p}=0.64\right)$.

613

614 Figure 4. Relationship between residual horn length and the difference in

615 allometric slope between minor and major males $\left(\mathrm{R}^{2}=0.36, \mathrm{~F}_{1,28}=17.3, \mathrm{p}<0.001\right)$.

616 

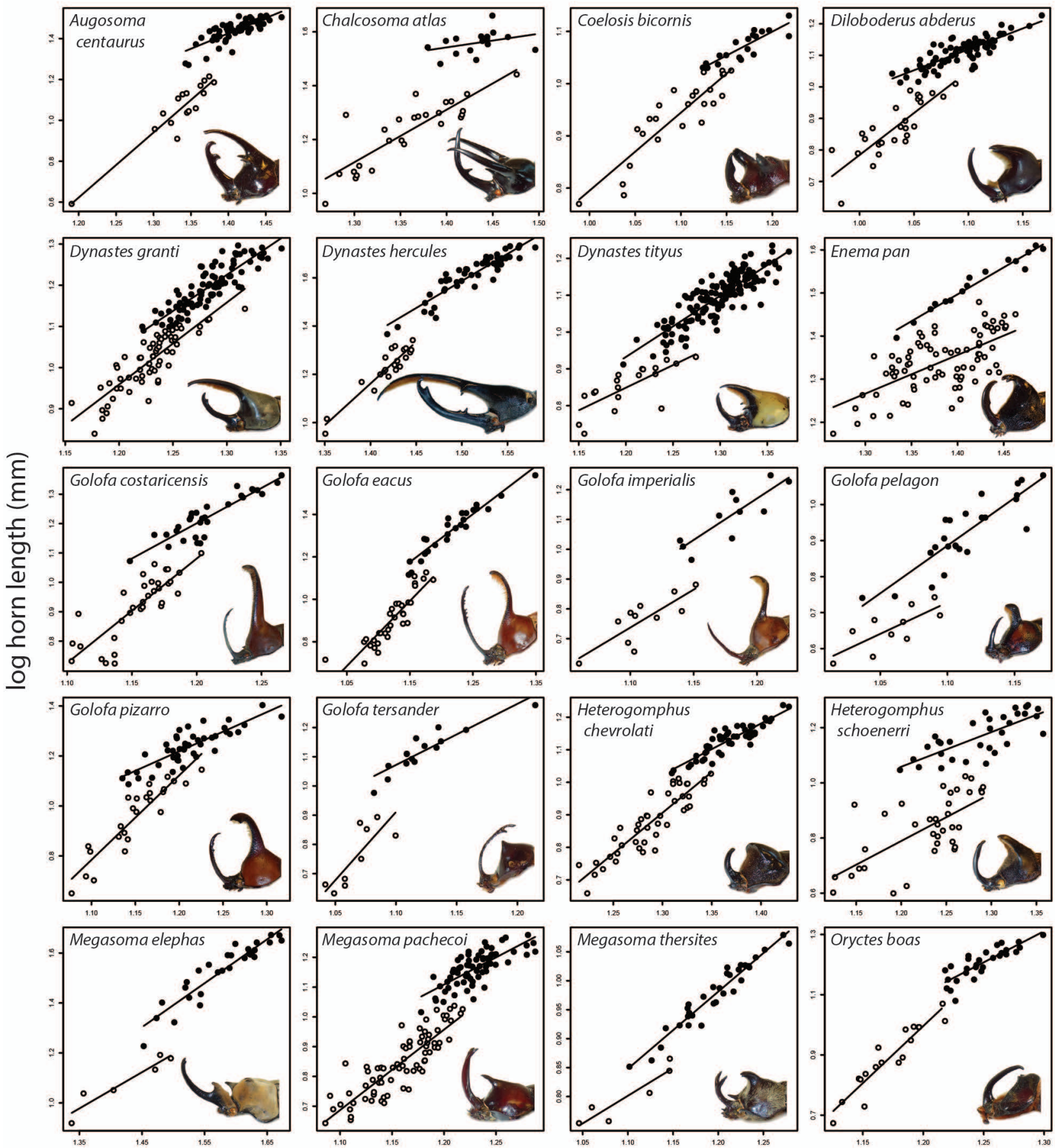

log prothorax width $(\mathrm{mm})$ 
Figure $\mathbf{l b}$

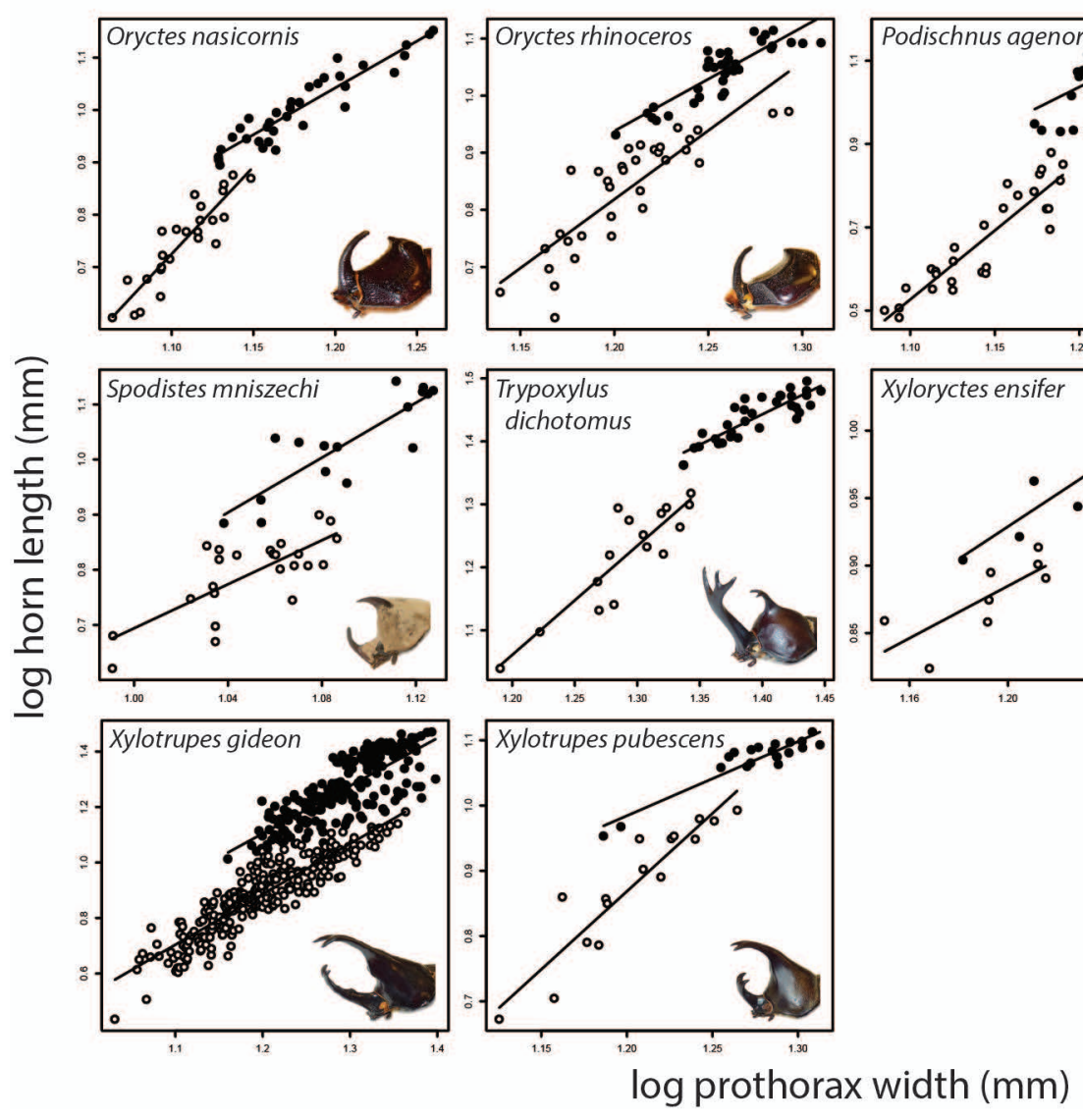


Figure 2

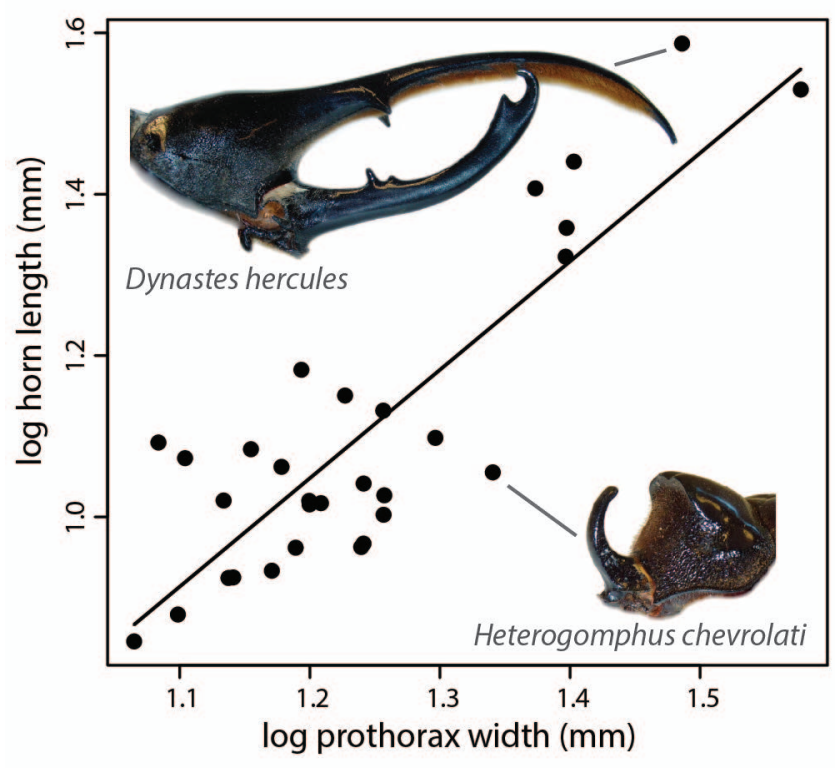


Figure 3
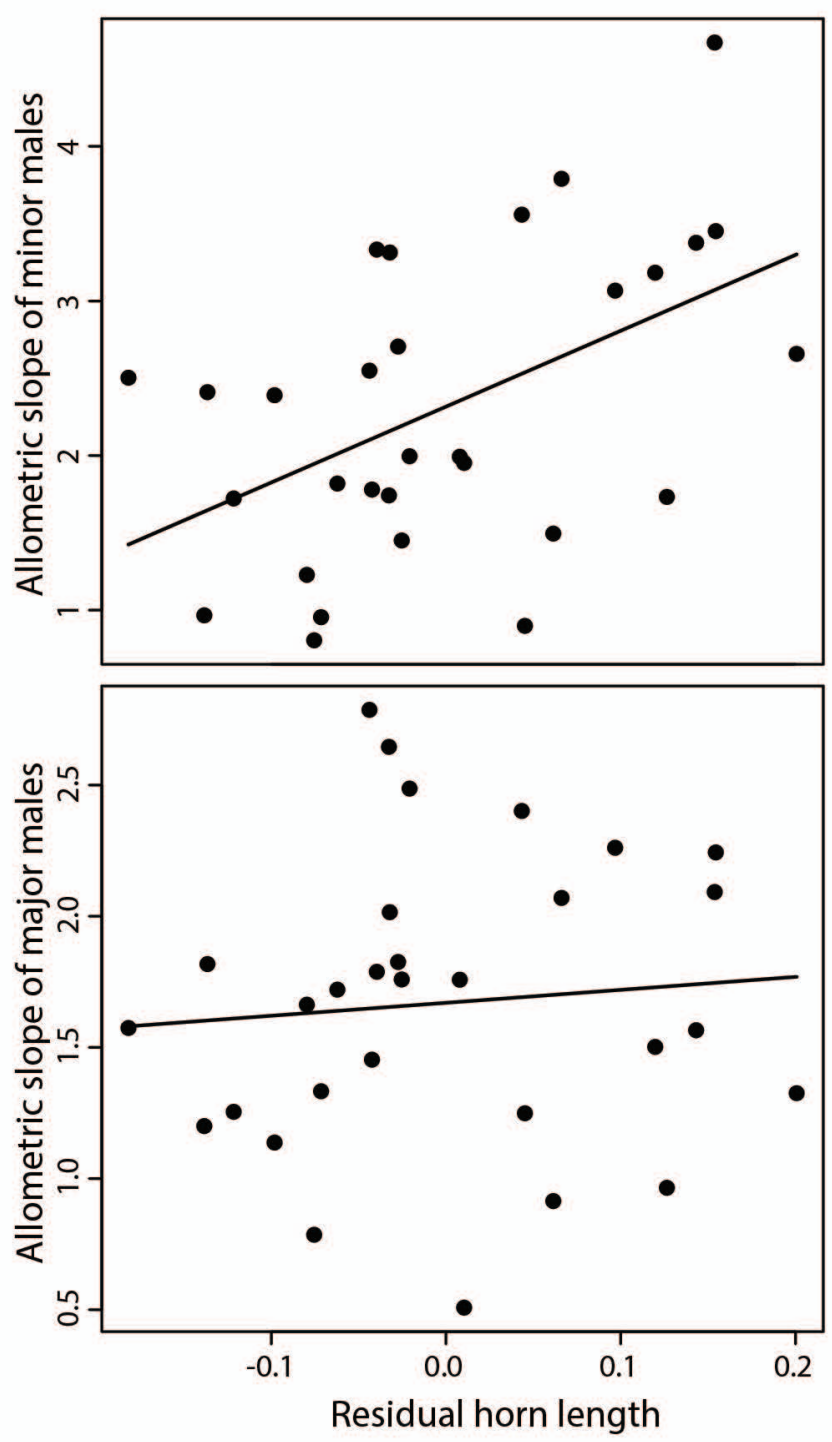
Figure 4

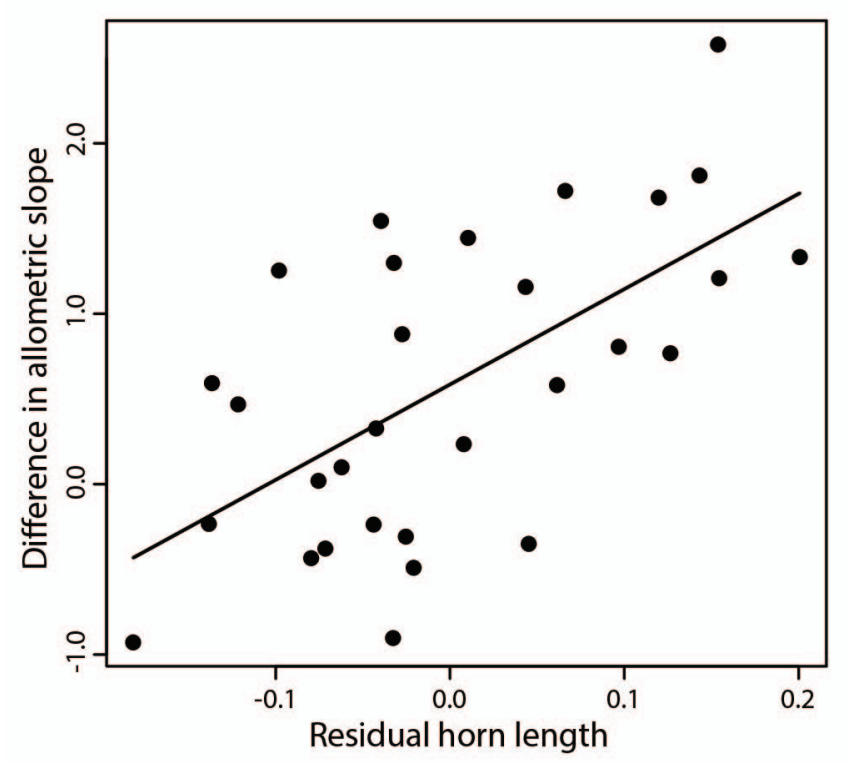

